\title{
Gene alterations by peroxisome proliferator-activated receptor $\gamma$ agonists in human colorectal cancer cells
}

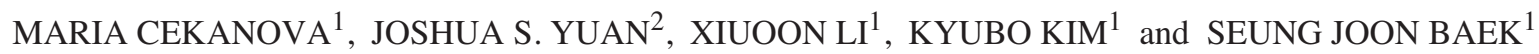 \\ ${ }^{1}$ Laboratory of Environmental Carcinogenesis, Department of Pathobiology, College of Veterinary Medicine, \\ ${ }^{2}$ UTIA Genomics Hub, The University of Tennessee, Knoxville, TN 37996, USA
}

Received October 24,2007; Accepted December 27, 2007

\begin{abstract}
The peroxisome proliferator-activated receptor $\gamma$ $(\operatorname{PPAR} \gamma)$ is a nuclear transcription factor that controls the genes involved in metabolism and carcinogenesis. In the present study, we examined the alteration of gene expression in HCT-116 human colorectal cancer cells by PPAR $\gamma$ agonists: MCC-555 $(5 \mu \mathrm{M})$, rosiglitazone $(5 \mu \mathrm{M})$, and 15-deoxy$\Delta^{12,14}$-prostaglandin $\mathbf{J}_{2}(1 \mu \mathrm{M})$. The long-oligo microarray data revealed a list of target genes commonly induced (307 genes) and repressed (32 genes) by tested PPAR $\gamma$ agonists. These genes were analyzed by Onto-Express software and KEGG pathway analysis and revealed that PPAR $\boldsymbol{y}$ agonists are involved in cell proliferation, focal adhesion, and several signaling pathways. Eight genes were selected to confirm the microarray data by RT-PCR and real-time PCR, from which CSTA, DAP13, TAF12, RIS1, CDKN3 and MAGOH were up-regulated, and KLHL11 and NCOA2 were downregulated. This study elucidates the commonly induced genes modulated by tested PPAR $\boldsymbol{\gamma}$ ligands involved in the different signaling pathways and metabolisms, probably mediated in a PPAR $\boldsymbol{\gamma}$-dependent manner in colorectal cancer cells and helps to better understand the pleiotropic actions of PPAR $\gamma$ ligands.
\end{abstract}

\section{Introduction}

The peroxisome proliferator-activated receptors (PPARs) are members of the nuclear hormone receptor family and are activated by agonists that directly bind transcription factors to regulate the target genes (1). At present, three types of

Correspondence to: Dr Seung Joon Baek, Department of Pathobiology, College of Veterinary Medicine, The University of Tennessee, 2407 River Drive, Knoxville, TN 37996, USA

E-mail: sbaek2@utk.edu

Abbreviations: PPAR, peroxisome proliferator-activated receptor; $\mathrm{PGJ}_{2}, 15$-deoxy- $\Delta^{12,14}$-prostaglandin $\mathrm{J}_{2}$; RGZ, rosiglitazone; PPRE, peroxisome proliferator response element; TGZ, troglitazone

Key words: MCC-555, rosiglitazone, colon cancer, PPAR, microarray
PPARs have been identified (PPAR $\alpha, \operatorname{PPAR} \beta / \delta$ and PPAR $\gamma$ ), each with different functions, tissue distributions and activations. Among them, PPAR $\boldsymbol{y}$ is highly expressed in adipose and colon tissue, and marginally expressed in the heart, skeletal muscle and liver tissues (2). The PPAR $\gamma$ activation by agonists regulates adipocyte differentiation and promotes lipid storage in mature adipocytes. The PPAR $\gamma$ agonists can also affect cell proliferation, differentiation, and apoptosis in a PPAR $\boldsymbol{\gamma}$-dependent and/or independent manner and thereby represent a potentially important therapeutic approach to cancer treatments (1). Thus, many studies describe beneficial effects of the PPAR $\gamma$ agonists for treatment of different types of cancer (3-7), including colorectal carcinoma $(8,9)$.

Agonists of PPAR $\boldsymbol{y}$ include prostaglandins of the $\mathrm{J}$ series $\left(\mathrm{PGJ}_{2}\right)$; the synthetic antidiabetic thiazolidinediones, such as troglitazone (TGZ), rosiglitazone (RGZ), and MCC-555; and oxidative metabolites of polyunsaturated fatty acids. Both TGZ and $\mathrm{PGJ}_{2}$ affect several pathways in a PPAR $\boldsymbol{\gamma}$ independent manner: TGZ induces the p53 pathway (10), inhibits cholesterol biosynthesis (11), inhibits translation initiation (12), and promotes antioxidant function (13), whereas $\mathrm{PGJ}_{2}$ induces apoptosis (14) and affects signaling pathways including Erk1/2 and NF-кB (15). We have also recently demonstrated that TGZ induces the early growth response gene (EGR-1) independently of PPAR $\gamma$ transcription factor activation (8) and that MCC-555 induces apoptosis in HCT-116 cells, independently of PPAR $\gamma$ (16). Thus, the anti-cancer activity of the PPAR $\boldsymbol{\gamma}$ agonists should be explored both dependently and independently at the levels of transcription in several cancer types.

The objective of this study was to investigate the pattern of genes commonly modulated by three PPAR $\gamma$ agonists (MCC-555, RGZ and $\mathrm{PGJ}_{2}$ ) in human HCT-116 colorectal cancer cells. The long-oligo microarray was employed and the data revealed a list of target genes commonly induced by tested PPAR $\boldsymbol{\gamma}$ agonists. The pattern of altered genes was evaluated by cluster analysis, and the commonly regulated genes were analyzed by ontology and signaling pathway analysis, to better understand the biological profiles involved in PPAR $\boldsymbol{\gamma}$ dependency. In addition, common genes involved in up-regulation (307 genes) and down-regulation (32 genes) by PPAR $\gamma$ agonists were analyzed and were shown to play important roles in cell proliferation, apoptosis, cell adhesion, 
energy homeostasis, insulin metabolism and other signaling pathways. Eight genes were selected for further analysis, of which 6 displayed higher mRNA expression in PPAR $\gamma$ agonist-treated HCT-116 cells than in untreated control: (DAP13) $13 \mathrm{kDa}$ differentiation-associated protein cystatin A (CSTA), NADH dehydrogenase $1 \alpha$ subcomplex 12, $20 \mathrm{kDa}$ TATA box binding protein (TBP)-associated factor (TAF12), Ras-induced senescence 1 (RIS1), cyclin-dependent kinase inhibitor 3 (CDKN3) and mago-nashi homolog (Drosophila) proliferation-associated (MAGOH). We also determined that two genes displayed down-regulation of mRNA expression: kelch-like 11 (KLHL-11) and nuclear receptor coactivator 2 (NCOA2). This study identified several human genes that were commonly expressed by PPAR $\boldsymbol{\gamma}$ agonists in human colorectal cancer cells, and this report describes their possible cellular and physiological roles in PPAR $\boldsymbol{\gamma}$-dependent tumor growth.

\section{Materials and methods}

Cell lines. Human colorectal adenocarcinoma cell line HCT-116 was obtained from American Type Culture Collection (ATCC, Manassas, VA). The cells were maintained in McCoy's 5A modified medium supplemented with $10 \%$ fetal bovine serum, $100 \mathrm{IU}$ penicillin, and $100 \mu \mathrm{g} / \mathrm{ml}$ streptomycin and grown in an atmosphere of $5 \% \mathrm{CO}_{2}$ at $37^{\circ} \mathrm{C}$.

Materials. 5-[[6-[(2-fluorophenyl)-methoxy]-2-napthalenyl] methyl]-2,4-thiazolidinedione (MCC-555), rosiglitazone (RGZ) and 15-deoxy- $\Delta^{12,14}$-prostaglandin $\mathrm{J}_{2}\left(\mathrm{PGJ}_{2}\right)$ were purchased from Cayman Chemical Co. (An Arbor, MI). All other chemicals and reagents were purchased from Fischer Scientific, unless otherwise specified.

Plasmids, transient transfections and luciferase assay. The tk-PPREx3-Luc reporter plasmid, a PPAR-dependent luciferase construct, was generously provided by Dr Ron M. Evans (Salk Institute, La Jolla, CA). All transfection experiments were performed using Lipofectamine reagent (Invitrogen Corp., Carlsbad, CA) according to the manufacturer's instructions. Briefly, HCT-116 cells were seeded $2 \times 10^{5}$ cells per well in 12 -well tissue culture plates in complete media overnight. Then the cells were co-transfected with $0.5 \mu \mathrm{g}$ tk-PPREx3-Luc reporter plasmid and $0.05 \mu \mathrm{g}$ pRL-null plasmid. After 5-h transfection, the media were replaced with complete media overnight, and cells were treated with different PPAR $\gamma$ agonists (5 $\mu \mathrm{M}$ MCC-555, $5 \mu \mathrm{M}$ $\mathrm{RGZ}$, or $1 \mu \mathrm{M} \mathrm{PGJ}_{2}$ ) for an additional $24 \mathrm{~h}$. The luciferase assay was performed using the Dual-Glo luciferase assay kit (Promega Corp., Madison, WI) according to the manufacturer's protocol. Produced luminescence was measured by a luminometer (TD-20/20, Turner Designs, Sunnyvale, CA) and data were analyzed by the Student's t-test. The results at ${ }^{*} \mathrm{p}<0.05,{ }^{* *} \mathrm{p}<0.01$ and ${ }^{* * *} \mathrm{p}<0.001$ were considered statistically significant.

RNA isolation for microarray analysis. HCT-116 cells were grown in $100-\mathrm{mm}$ dishes $\left(2 \times 10^{6}\right)$ in complete media overnight, and then washed twice with PBS and treated with $5 \mu \mathrm{M}$ MCC-555, $5 \mu \mathrm{M}$ RGZ, or $1 \mu \mathrm{M} \mathrm{PGJ}_{2}$ in serum-free media for an additional $24 \mathrm{~h}$. Total RNA was isolated from treated cell samples using an RNeasy mini kit (Qiagen, Valencia, CA).

Microarray labeling and hybridization. HEEBO long-oligo microarray slides were purchased from Microarray Inc. (Nashville, TN) based on a probe set designed by Illumina (San Diego, http://www.illumina.com) and Stanford University. The HEEBO long-oligo set contains about 39,000 probes for exonic regions and alternative spliced transcripts. Total RNA $(1 \mu \mathrm{g})$ was labeled for each sample with a SuperScript III Labeling Kit (Invitrogen) according to the manufacturer's instructions. The purified probes from both control and treated samples were mixed and hybridized with the long-oligo microarray using a microarray hybridization kit (Corning, Inc., Corning, NY) on a MAUI hybridization station (Bio Micro Systems Inc., Salt Lake City, UT) according to the manufacturer's instruction. Dye swap experiments were included to eliminate dye-specific bias. For each sample set of treated vs. control, the treated mRNA was first labeled with Cy5 and the control with Cy3. In the reverse experiment, the labeling dyes were swapped. The two labeling reactions and microarray hybridizations were performed in parallel. Considering the reverse labeling experiments, a total of two biological replicates and two technical replicates of the experiment were performed.

Microarray data processing. After hybridization, the microarray slides were washed and scanned in a GenePix 4000 scanner (Axon Instrument, Union City, CA), and the images were processed by GenePix Pro 4.0 software (Axon Instrument). The resultant file was analyzed with Bioconductor (http://www.bioconductor.org), where local background subtraction and lowess normalization were carried out for each microarray slide. The biological replicates and technical replicates were considered differently in the analysis. Linear models from the limma package of Bioconductor were applied to derive a p-value and average of logarithm 2-based ratio. Changes in gene expression pattern were considered statistically significant at ${ }^{*} p<0.05$. A ratio cut-off of 1.5 and degree of freedom higher or equal to two (represents the changes of gene expression on at least three slide replicates of same experiment) were included as quality controls. The ratio cut-off of 1.5 in gene expression was selected because the action of PPAR $y$ agonists are diverse in gene profiles; so to obtain the list of genes that are commonly down-regulated, we had to decrease the cut-off to a 1.5-fold instead of a 2-fold change as is commonly adopted for microarray data analysis.

In order to evaluate the microarray quality, the M vs. A plot was generated as a scatter plot of $\log$ intensity ratios $\mathrm{M}=\log _{2}(\mathrm{R} / \mathrm{G})$ vs. average $\log$ intensities $\mathrm{A}=\log _{2}(\mathrm{RxG}) / 2$, where $R$ and $G$ represent the fluorescence intensities in the red $(R)$ and green $(G)$ channels, respectively. Scatter plots were generated to compare the signal strength between slides to evaluate the reproducibility of the experiments. Hierarchical clustering was carried out to cluster among the genes and among the samples with Mev4.0 software from TIGR (The Institute of Genome Research). For the gene ontology analysis and identification of signaling pathways, 
Table I. Primer sequences used for RT-PCR.

\begin{tabular}{|c|c|c|}
\hline Gene & $\begin{array}{l}\text { Forward }(\mathrm{F}) \text { and } \\
\text { reverse }(\mathrm{R}) \text { primers }\end{array}$ & $\begin{array}{l}\text { PCR product } \\
\text { size (bp) }\end{array}$ \\
\hline CSTA & $\begin{array}{l}\text { F: 5'-ggcttatctgaggccaaacc-3' } \\
\text { R: 5'-tttgtccgggaagacttttg-3' }\end{array}$ & 217 \\
\hline DAP13 & $\begin{array}{l}\text { F: 5'-gcgaggcaagatggagttag-3' } \\
\text { R: 5'-ttccatccacatcccagaat-3' }\end{array}$ & 248 \\
\hline TAF12 & $\begin{array}{l}\text { F: 5'-gcaagtctagcaccctggag-3' } \\
\text { R: 5'-attgctgtccattccetgac-3' }\end{array}$ & 201 \\
\hline RIS1 & $\begin{array}{l}\text { F: 5'-cttccagttccgaaaagcag-3' } \\
\text { R: 5'-ttggtcattttctgccatga-3' }\end{array}$ & 165 \\
\hline CDKN3 & $\begin{array}{l}\text { F: 5'-catagccagctgctgtgaaa-3' } \\
\text { R: 5'-cccggatcctcttaggtctc-3' }\end{array}$ & 190 \\
\hline SEC61B & $\begin{array}{l}\text { F: 5'-tgttccagtattggttatgagtcttctg-3' } \\
\text { R: 5'-cgagtgtacttgecccaaatg-3' }\end{array}$ & 75 \\
\hline MAGOH & $\begin{array}{l}\text { F: 5'-ccaaagaggatgatgcattgtg-3' } \\
\text { R: 5'-ttcatctccaatgacgatttcaag-3' }\end{array}$ & 77 \\
\hline KLHL-11 & $\begin{array}{l}\text { F: 5'-tcggaaagaagcctaccgatatt-3' } \\
\text { R: 5'-ctctacaacgaggttgtggcatag-3' }\end{array}$ & 80 \\
\hline $\mathrm{NCOA} 2$ & $\begin{array}{l}\text { F: 5'-aatgcatcagcaacagcaag-3' } \\
\text { R: 5'-ataagtgggctctggggagt-3' }\end{array}$ & 225 \\
\hline TBP & $\begin{array}{l}\text { F: 5'-gcccgaaacgccgaatat-3' } \\
\text { R: 5'-ccgtggttcgtggctctct-3' }\end{array}$ & 73 \\
\hline GAPDH & $\begin{array}{l}\text { F: 5'-gaccacagtccatgccatcact-3' } \\
\text { R: 5'-tccaccaccetgttgctgtag-3' }\end{array}$ & 560 \\
\hline
\end{tabular}

we used Onto-Express software (Onto-Express and Pathway analysis, Intelligent Systems and Bioinformatics Laboratory, Detroit, MI).

Reverse transcription PCR. HCT-116 cells were grown in 60-mm dishes $\left(1 \times 10^{6}\right)$ in complete media overnight, and then washed twice with PBS and treated with MCC-555 (5, 10 and $50 \mu \mathrm{M}), \operatorname{RGZ}(5,10$ and $50 \mu \mathrm{M})$, or $\mathrm{PGJ}_{2}(1,2$ and $10 \mu \mathrm{M})$ in serum-free media for an additional $24 \mathrm{~h}$. Total RNA was isolated from treated cell samples using an RNeasy mini kit (Qiagen), and then cDNA was synthesized from $1 \mu \mathrm{g}$ of total RNA using an iScript cDNA Synthesis kit (Bio-Rad, Hercules, CA) according to the manufacturer's protocols. Synthesized cDNA $(1 \mu \mathrm{g})$ was then added to a $20 \mu 1$ PCR reaction mixture (GoTaq Green Master Mix PCR Reaction Mixture, Promega, Madison, WI) with each set of gene-specific primers. The primer sequences are described in Table I in detail. The final PCR products were loaded to agarose gels and photographed under UV light. The experiments were repeated in three independent replicates. The densitometries of the captured images were evaluated by Scion Image Software (Frederick, MD), and were shown on the final chart with mean \pm SE values for each treatment. The
Student's unpaired t-test was used to analyze the statistical significance.

Quantitative real-time-PCR. Complementary DNA samples were diluted into $10 \mathrm{ng} / \mu 1,0.1 \mathrm{ng} / \mu 1$ and $0.01 \mathrm{ng} / \mu 1$ concentration series. Three replicates of real-time PCR experiments were performed for each concentration using an ABI 7000 Sequence Detection System from AB Applied Biosystems (Foster City, CA) with the ABsolute QPCR SYBR-Green mix (ABgene House, Epsom, UK). The primers for target genes were designed by Primer Express software (AB Applied Biosystems) and the primers sequences are listed in Table I. The gene for TATA binding protein (TBP) was used as an internal control. After the real-time PCR experiments, $\mathrm{Ct}$ numbers were extracted for both reference genes and target genes with auto baseline and manual threshold. Amplification efficiency for the reactions was estimated as described previously (17), and multiple regression models were used to derive point estimation of $\Delta \Delta \mathrm{Ct}, \mathrm{p}$-value, standard error and $95 \%$ confidence intervals with the SAS 9.1 programs provided (SAS Institute).

Statistical analysis. We used SAS 9.1 (SAS Institute) or Student's unpaired t-test to analyze the data. Results were considered statistically significant at ${ }^{*} \mathrm{p}<0.05,{ }^{* *} \mathrm{p}<0.01$ and ${ }^{* * *} \mathrm{p}<0.001$.

\section{Results}

Transcriptional activation of the PPAR receptor by PPAR agonists in HCT-116 cells. Agonists of the PPARy receptor are known to possess anti-diabetic, anti-inflammatory and anti-cancer effects. In our study, we used three PPAR $\gamma$ agonists: two from the synthetic family of thiazolidinediones (MCC-555 and RGZ), and one naturally occurring metabolite of arachidonic acid $\left(\mathrm{PGJ}_{2}\right)$ (Fig. 1A). To confirm that all three tested compounds are able to activate PPAR $\boldsymbol{\gamma}$ and transcribe genes containing PPAR $\gamma$ binding sites in HCT-116 cells, a reporter construct, tk-PPREx3-Luc, was transfected and treated with the indicated PPAR $\gamma$ agonists, and luciferase activity was measured. It has been reported that HCT-116 cells highly express PPARy (18). As shown in Fig. 1B, treatment with $5 \mu \mathrm{M}$ MCC-555 demonstrates the highest transcriptional activation of the PPAR $\gamma$ receptor by 4.93 -fold induction $(\mathrm{p}<0.001)$ as compared to the other PPAR $\gamma$ agonists, RGZ and $\mathrm{PGJ}_{2}$ with 2.54- $(\mathrm{p}<0.001)$ and 1.37-fold $(p<0.01)$ inductions, respectively. This result suggests that HCT-116 cells express functionally active PPAR $\gamma$ proteins that are responsible for PPAR $\boldsymbol{y}$ agonists.

Transcriptional responses of PPAR $\gamma$ agonists in HCT-116 cells. To examine the transcriptional responses of PPAR $\gamma$ agonists, gene expression patterns were compared in MCC555-, RGZ- and $\mathrm{PGJ}_{2}$-treated HCT-116 cells using longoligo microarrays containing the HEEBO oligo set. In our experiments, the cells were treated with $5 \mu \mathrm{M}$ MCC-555, $5 \mu \mathrm{M}$ RGZ and $1 \mu \mathrm{M} \mathrm{PGJ}_{2}$ for $24 \mathrm{~h}$, and then total RNAs were isolated and processed for the microarray experiment as described in Materials and methods. Experiments for each treatment group were carried out in four replicates. Genes 
A<smiles>CC(C)(S)[SH2+](C)(C)C</smiles><smiles></smiles><smiles>CCCCC/C=C\C=C\C1C(=O)C=C[C@H]1NC(=O)O[Na]</smiles>

B

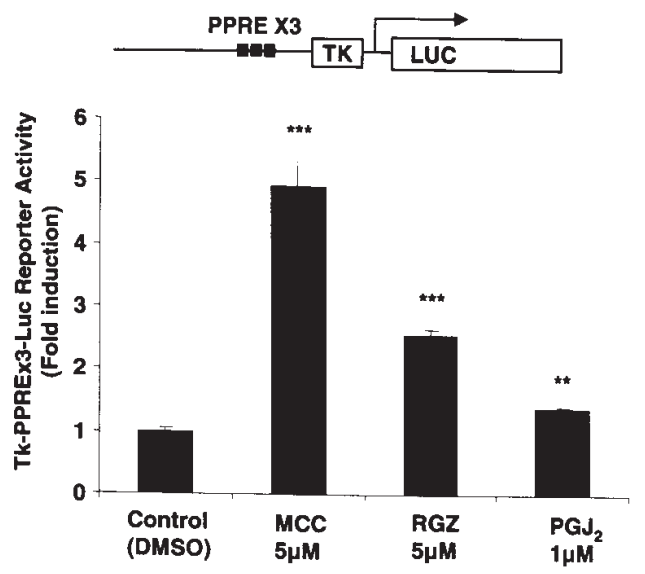

Figure 1. Transcriptional activation of the PPAR $y$ receptor in HCT-116 cells by PPAR $\gamma$ agonists. (A) Molecular structures of three PPAR $\gamma$ agonists used in this study, MCC-555 (MCC), rosiglitazone (RGZ) and 15-deoxy- $\Delta^{12,14}$ prostaglandin $\mathrm{J}_{2}\left(\mathrm{PGJ}_{2}\right)$. (B) Transcriptional activation of the PPAR $\gamma$ receptor in HCT-116 cells transfected with tk-PPREx3-Luc reporter plasmid, and then treated with different PPAR $\gamma$ agonists, MCC-555 $(5 \mu \mathrm{M}), \operatorname{RGZ}(5 \mu \mathrm{M})$ and $\mathrm{PGJ}_{2}(1 \mu \mathrm{M})$ for $24 \mathrm{~h}$.

modulated by PPAR $\boldsymbol{\gamma}$ agonists with statistical significance between the experimental groups (vehicle vs. treatments) were identified by SAS statistical software. Changes in gene expression patterns were considered statistically significant at $p<0.05$ if present in at least three replicates (degree of freedom 2). To evaluate the quality of microarray data, the $M$ vs. A plot was generated to plot logarithm 2-based two color

A

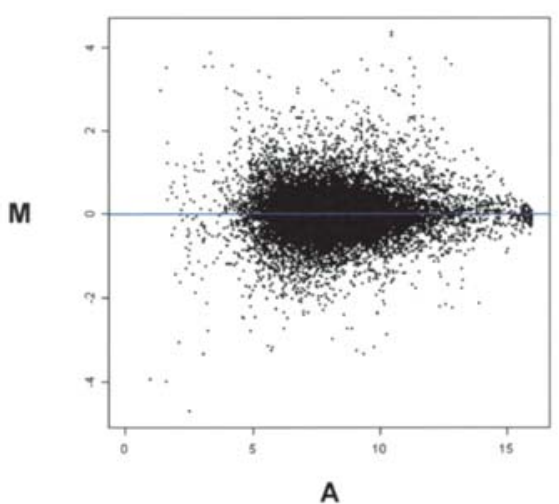

C

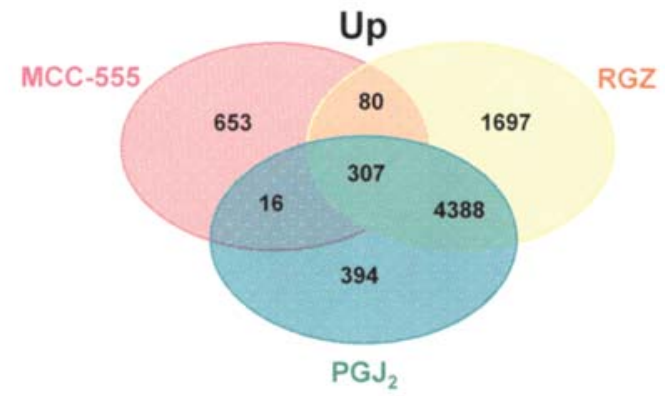

B

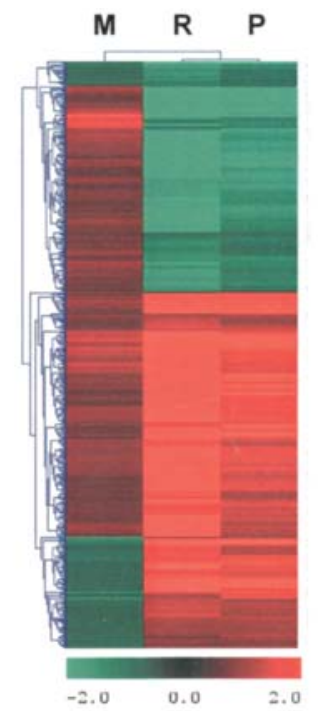

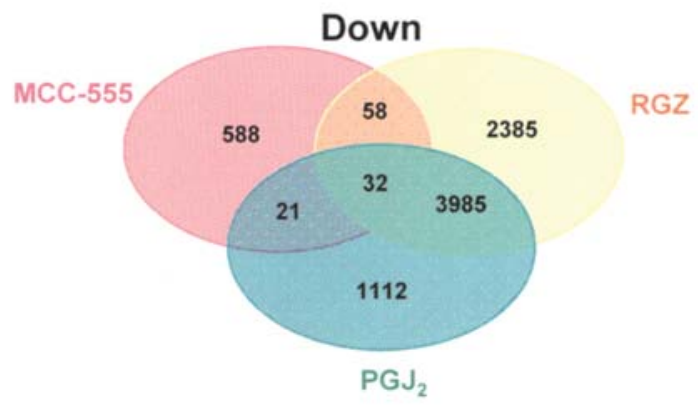

Figure 2. Microarray data quality and analysis. (A) In order to evaluate the hybridization quality of microarrays, the M vs. A plot was generated as a scatter plot of $\log$ intensity ratios $M=\log _{2}(R / G)$ vs. average $\log$ intensities $A=\log _{2}(R x G) / 2$, where $R$ and $G$ represent the fluorescence intensities in the red and green channels, respectively. The M vs. A plot for the normalized average of MCC-555 treatments (4 slides) shows an even distribution of down-regulated and up-regulated genes across different signal intensities. (B) Hierarchical cluster map of gene expression. The expression matrix displays genes that were differentially expressed in HCT-116 cells treated by PPAR $\gamma$ agonists. For cluster analysis of the logarithm 2-based gene expression ratio for treatment by MCC-555, RGZ and $\mathrm{PGJ}_{2}$ (green color down-regulated genes, red color up-regulated genes), we used the following selection criteria: i) at least 1.5-fold difference between untreated and PPAR $\gamma$ agonist-treated; ii) p-value for difference in expression $<0.05$ (SAS test); and iii) appearance of the signal in at least three slide microarray replicates from each treatment. (C) Bend diagrams with the up- and down-regulated genes by MCC-555, RGZ and PGJ ${ }_{2}$ treatments. 
Table II. List of commonly 20 up-regulated genes by tested PPAR $\gamma$ ligands, MCC-555, RGZ and PGJ $(\mathrm{p}<0.05$, fold change or ratio >1.5) in HCT-116 cells.

\begin{tabular}{|c|c|c|c|c|c|c|c|}
\hline \multicolumn{2}{|r|}{ Gene } & \multicolumn{2}{|c|}{ MCC-555 } & \multicolumn{2}{|c|}{ RGZ } & \multicolumn{2}{|c|}{$\mathrm{PGJ}_{2}$} \\
\hline Symbol & Description & p-value & Ratio & $\mathrm{p}$-value & Ratio & p-value & Ratio \\
\hline CSTA & Cystatin A (stefin A) & $5.73 \mathrm{E}-05$ & 4.238 & $5.80 \mathrm{E}-05$ & 4.18 & 0.0307297 & 2.521 \\
\hline UQCRB & $\begin{array}{l}\text { Ubiquinol-cytochrome } \mathrm{c} \\
\text { reductase binding protein }\end{array}$ & 0.000269 & 3.079 & 0.0058807 & 5.967 & 0.0019013 & 4.975 \\
\hline COX17 & $\begin{array}{l}\text { COX17 homolog, cytochrome c } \\
\text { oxidase assembly protein (yeast) }\end{array}$ & $8.76 \mathrm{E}-05$ & 3.031 & 0.0049923 & 5.282 & 0.0153466 & 4.09 \\
\hline COX7A2 & $\begin{array}{l}\text { Cytochrome c oxidase subunit } \\
\text { VIIa polypeptide } 2 \text { (liver) }\end{array}$ & $4.51 \mathrm{E}-05$ & 3.011 & 0.0008634 & 6.178 & 0.0015228 & 3.651 \\
\hline COMMD6 & COMM domain containing 6 & 0.000369 & 2.941 & 0.0013956 & 8.212 & 0.0009533 & 4.718 \\
\hline LOC257039 & $\begin{array}{l}\text { PREDICTED: similar to } \\
\text { ribosomal protein } \mathrm{S} 17\end{array}$ & 0.000358 & 2.935 & 0.0020001 & 6.81 & 0.0045161 & 5.811 \\
\hline MT1J & Metallothionein $1 \mathrm{~J}$ & 4.04E-05 & 2.917 & 0.0001288 & 5.131 & 0.0204116 & $2.51 \mathrm{c}$ \\
\hline LOC392487 & $\begin{array}{l}\text { PREDICTED: similar to } \\
\text { ribosomal protein L31 }\end{array}$ & 0.000151 & 2.882 & 0.0055197 & 5.187 & 0.0029512 & 3.77 \\
\hline LOC130865 & $\begin{array}{l}\text { PREDICTED: similar to } 60 \mathrm{~S} \\
\text { ribosomal protein L26-like } 1\end{array}$ & 0.000822 & 2.837 & 0.0254389 & 4.847 & 0.0091955 & 4.598 \\
\hline LOC391581 & $\begin{array}{l}\text { PREDICTED: similar to } \\
\text { ribosomal protein L31 }\end{array}$ & 0.000445 & 2.835 & 0.0006942 & 8.253 & 0.0072957 & 3.713 \\
\hline LOC440539 & $\begin{array}{l}\text { PREDICTED: similar to } \\
\text { ribosomal protein L37 }\end{array}$ & 0.000305 & 2.82 & 0.0003481 & 7.013 & 0.0020661 & 3.216 \\
\hline RPL37A & Ribosomal protein L37a & 0.002622 & 2.768 & $9.05 \mathrm{E}-05$ & 7.718 & 0.0003969 & 3.842 \\
\hline LOC343153 & $\begin{array}{l}\text { PREDICTED: similar to } \\
\text { ribosomal protein L26 }\end{array}$ & 0.00061 & 2.761 & 0.0026409 & 5.46 & 0.0063362 & 2.706 \\
\hline LOC402318 & $\begin{array}{l}\text { PREDICTED: similar to } \\
60 \text { S ribosomal protein L32 }\end{array}$ & 0.00186 & 2.749 & 0.0070023 & 7.32 & 0.012813 & 4.682 \\
\hline LOC391035 & $\begin{array}{l}\text { PREDICTED: similar to } \\
\text { ribosomal protein } \mathrm{S} 15 \mathrm{a}\end{array}$ & 0.003748 & 2.724 & 0.0033576 & 8.008 & 0.0149866 & 6.855 \\
\hline LOC402716 & $\begin{array}{l}\text { PREDICTED: similar to } \\
\text { 60S ribosomal protein L32 }\end{array}$ & 0.000397 & 2.709 & 0.0020859 & 6.651 & 0.0036407 & 3.235 \\
\hline RPS21 & Ribosomal protein S21 & 0.00065 & 2.677 & 0.0001934 & 6.545 & 0.0039326 & 2.584 \\
\hline LOC346950 & $\begin{array}{l}\text { PREDICTED: similar to } \\
\text { ribosomal protein L37 }\end{array}$ & 0.001874 & 2.648 & $3.20 \mathrm{E}-05$ & 8.496 & 0.0003481 & 7.725 \\
\hline COX17 & $\begin{array}{l}\text { COX17 homolog, cytochrome c } \\
\text { oxidase assembly protein (yeast) }\end{array}$ & 0.000491 & 2.645 & 0.0030994 & 5.341 & 0.0061663 & 2.955 \\
\hline NDUFC1 & $\begin{array}{l}\text { NADH dehydrogenase (ubiquinone) } 1 \text {, } \\
\text { subcomplex unknown, 1, } 6 \mathrm{kDa}\end{array}$ & 0.000198 & 2.635 & 0.0015227 & 6.358 & 0.0032387 & 3.841 \\
\hline
\end{tabular}

ratios against the logarithm 2-based two color signal strength multiples (Fig. 2A), indicating even distribution of downregulated and up-regulated genes across different signal intensities. Scatter plots were also generated to compare the signal strengths between slides to evaluate the reproducibility of the experiments and microarray data quality (data not 


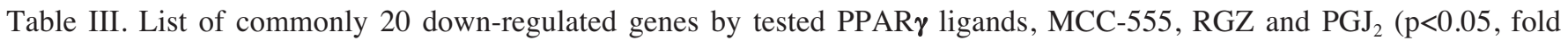
change or ratio $<0.667)$ in HCT-116 cells

\begin{tabular}{|c|c|c|c|c|c|c|c|}
\hline \multicolumn{2}{|r|}{ Gene } & \multicolumn{2}{|c|}{ MCC-555 } & \multicolumn{2}{|c|}{ RGZ } & \multicolumn{2}{|c|}{$\mathrm{PGJ}_{2}$} \\
\hline Symbol & Description & p-value & Ratio & p-value & Ratio & p-value & Ratio \\
\hline FAM13A1 & $\begin{array}{l}\text { Family with sequence similarity } 13 \text {, } \\
\text { member A1 }\end{array}$ & 0.045278 & 0.399 & 0.0001102 & 0.307 & 0.0062549 & 0.485 \\
\hline ARID5B & $\begin{array}{l}\text { AT rich interactive domain 5B } \\
\text { (MRF1-like) }\end{array}$ & 0.000568 & 0.428 & 0.0010759 & 0.41 & 0.0407399 & 0.587 \\
\hline MDM2 & $\begin{array}{l}\text { Mdm2, transformed } 3 \mathrm{~T} 3 \text { cell double } \\
\text { minute } 2, \text { p53 binding protein (mouse) }\end{array}$ & 0.041641 & 0.504 & 0.0001257 & 0.289 & 0.0091824 & 0.44 \\
\hline TEF & Thyrotrophic embryonic factor & 0.001256 & 0.527 & 0.0030892 & 0.373 & 0.0211248 & 0.491 \\
\hline NCOA2 & Nuclear receptor coactivator 2 & 0.011429 & 0.55 & 0.0011083 & 0.228 & 0.0034108 & 0.271 \\
\hline FLJ36754 & P18SRP protein & 0.003659 & 0.568 & 0.0029843 & 0.374 & 0.0368733 & 0.599 \\
\hline ATXN1 & Ataxin 1 & 0.009137 & 0.575 & 0.0012633 & 0.367 & 0.0187268 & 0.453 \\
\hline KLHL11 & Kelch-like 11 (Drosophila) & 0.005889 & 0.581 & $7.68 \mathrm{E}-05$ & 0.151 & $5.34 \mathrm{E}-05$ & 0.2 \\
\hline D2S448 & $\begin{array}{l}\text { PREDICTED: melanoma } \\
\text { associated gene }\end{array}$ & 0.002008 & 0.589 & 0.0264569 & 0.46 & 0.0218527 & 0.516 \\
\hline ATP9A & $\begin{array}{l}\text { ATPase, class II, type 9A } \\
\text { (ATP9A), mRNA }\end{array}$ & 0.005898 & 0.589 & 0.0050552 & 0.288 & 0.0091849 & 0.384 \\
\hline LOC91664 & $\begin{array}{l}\text { Similar to zinc finger protein } 268 \text {, } \\
\text { clone IMAGE: } 3352268\end{array}$ & 0.001072 & 0.591 & 0.0009028 & 0.365 & 0.0435433 & 0.632 \\
\hline PDE5A & Phosphodiesterase 5A, cGMP-specific & 0.008455 & 0.591 & 0.0002081 & 0.26 & 0.000969 & 0.241 \\
\hline NLN & Neurolysin (metallopeptidase M3 family) & 0.014697 & 0.591 & 0.0013405 & 0.47 & 0.0288632 & 0.606 \\
\hline FLJ10707 & $\begin{array}{l}\text { PREDICTED: hypothetical } \\
\text { protein FLJ } 10707\end{array}$ & 0.010421 & 0.592 & 0.0140784 & 0.257 & 0.0015614 & 0.267 \\
\hline APPL & $\begin{array}{l}\text { Adaptor protein containing } \mathrm{pH} \text { domain, } \\
\text { PTB domain and leucine zipper motif } 1\end{array}$ & 0.003269 & 0.603 & 0.004938 & 0.307 & 0.0048149 & 0.41 \\
\hline ABAT & 4-aminobutyrate aminotransferase & 0.00488 & 0.612 & 0.0073504 & 0.365 & 0.0336587 & 0.5 \\
\hline SCN5A & $\begin{array}{l}\text { Sodium channel, voltage-gated, type V, } \\
\alpha \text { (long QT syndrome } 3 \text { ) }\end{array}$ & 0.002446 & 0.613 & 0.0020712 & 0.442 & 0.0275364 & 0.579 \\
\hline RECQL & RecQ protein-like (DNA helicase Q1-like) & 0.004036 & 0.618 & 0.0004371 & 0.406 & 0.0219375 & 0.536 \\
\hline INPP5D & $\begin{array}{l}\text { Inositol polyphosphate-5-phosphatase, } \\
145 \mathrm{kDa}\end{array}$ & 0.023678 & 0.618 & 0.0039209 & 0.481 & 0.0345667 & 0.607 \\
\hline SUV420H1 & $\begin{array}{l}\text { Suppressor of variegation 4-20 } \\
\text { homolog } 1 \text { (Drosophila) }\end{array}$ & 0.039171 & 0.624 & 0.0003402 & 0.359 & 0.0221746 & 0.517 \\
\hline
\end{tabular}

shown). Fig. 2B shows the hierarchical cluster analysis of the distance between genes regulated by PPAR $\gamma$ agonists. Interestingly, MCC-555 shows a unique pattern in gene expression, compared to that of RGZ and $\mathrm{PGJ}_{2}$. This result may support a previous report that MCC-555 is a dual agonist for PPAR $\boldsymbol{\gamma}$ and PPAR $\alpha$, whereas RGZ and $\mathrm{PGJ}_{2}$ are PPAR $\boldsymbol{\gamma}$ specific agonists (16). As shown in Fig. 2C, microarray data showed that MCC-555 $(5 \mu \mathrm{M})$ treatment up-regulated 1056 genes and down-regulated 699 genes, RGZ $(5 \mu \mathrm{M})$ treatment up-regulated 6472 genes and down-regulated 6460 genes, and $\mathrm{PGJ}_{2}(1 \mu \mathrm{M})$ treatment up-regulated 5105 genes and down-regulated 5150 genes. Our results demonstrated that many genes were affected by PPAR $\boldsymbol{\gamma}$ agonists, suggesting that PPAR $\gamma$ agonists play a role in the regulation of numerous 


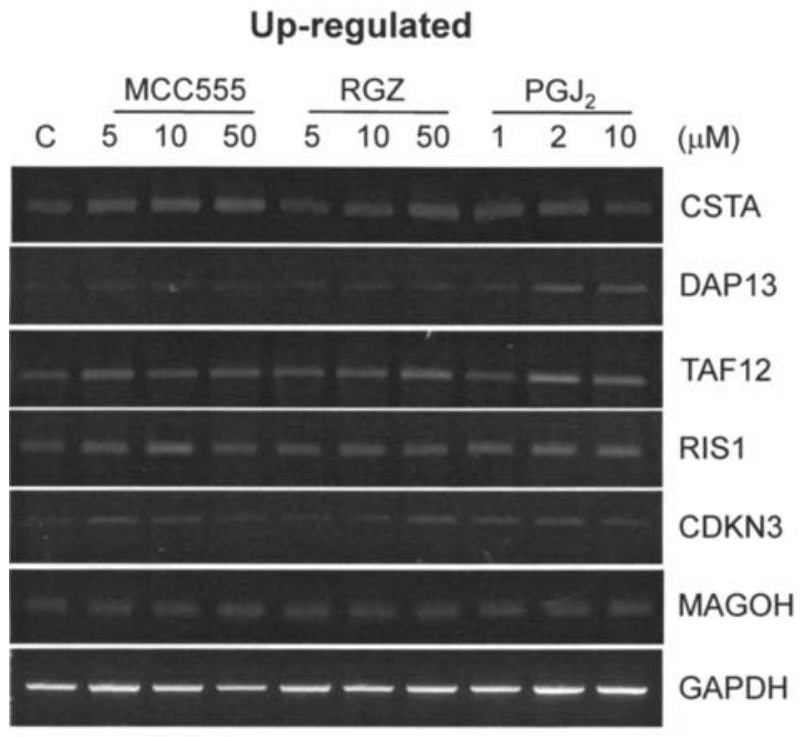

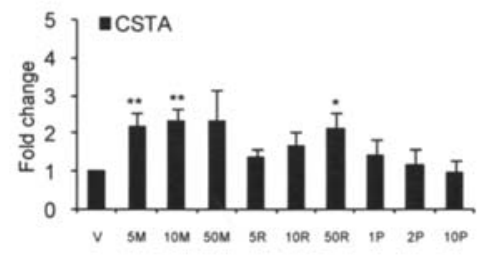
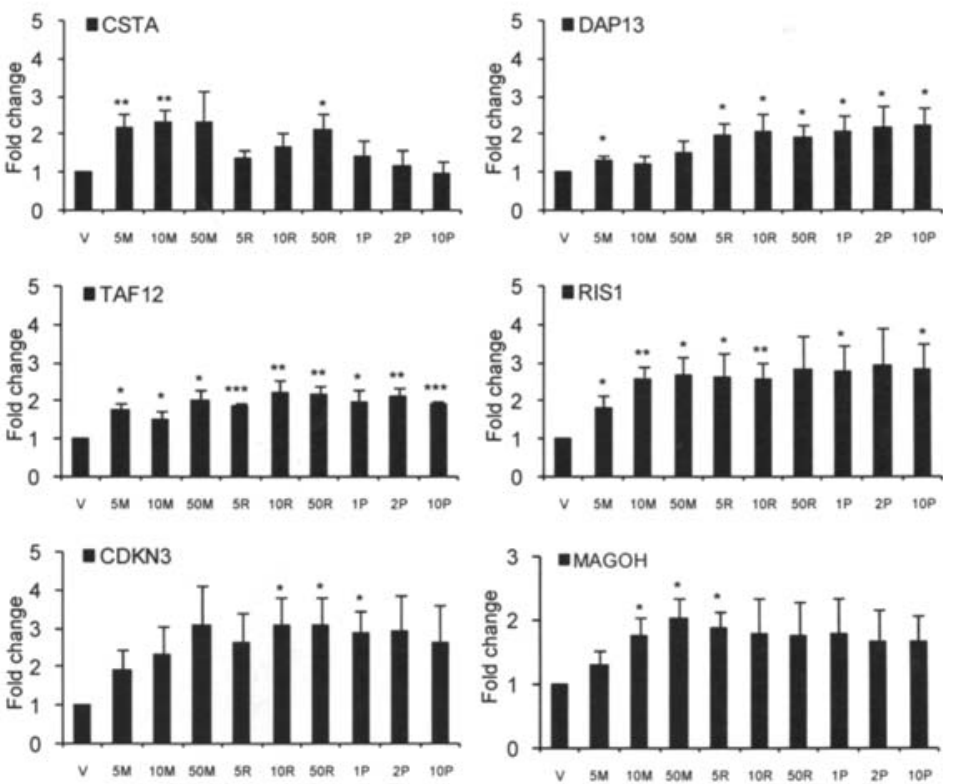

Figure 3. RT-PCR analysis of the selected PPAR $\gamma$ agonist-induced genes in HCT-116 cells. (A) HCT-116 cells were treated by different PPAR $\gamma$ agonists for $24 \mathrm{~h}$ as described in Materials and methods in detail. Six up-regulated genes (CSTA, DAP13, TAF12, RIS1, CDKN3 and MAGOH) characterized from our

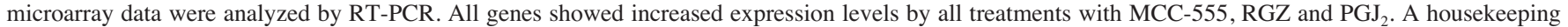
gene, GAPDH, was used for internal control and normalization. (B) Charts of the densitometry analysis of represented genes. Each chart represents the mean value $\pm \mathrm{SE}$ of three independent experiments.

signaling pathways in human colorectal cancer both in a PPAR $\boldsymbol{\gamma}$-dependent and independent manner. For further analysis, we focused on a group of genes commonly regulated by the tested PPAR $\boldsymbol{\gamma}$ agonists: 307 genes were commonly up-regulated and 32 genes commonly down-regulated. The list of top 20 genes commonly altered by PPAR $\boldsymbol{y}$ agonists are shown in Tables II and III with fold changes (ratios) and significant p-values. These genes were significantly modulated by all tested PPAR $\boldsymbol{\gamma}$ agonists, suggesting that alteration of these genes may act in a PPAR $\boldsymbol{\gamma}$-dependent manner.

RT-PCR analysis of selected genes modulated by PPARy agonists. We have examined the expression of selected genes by semi-quantitative reverse transcriptase (RT-PCR) in HCT-116 cells treated by MCC-555, RGZ and $\mathrm{PGJ}_{2}$ for $24 \mathrm{~h}$ as described in Materials and methods. We checked six commonly induced and two commonly repressed genes from our microarray data, based on the highest induction, p-value, and potential involvement in tumorigenesis. The six up-regulated genes are CSTA, DAP13, TAF12, RIS1, CDKN3 and MAGOH. As shown in Fig. 3, results of RT-PCR showed that the expression levels of these six genes increased in HCT-116 cells treated with the indicated PPAR $\gamma$ agonists and consistent with the result of microarray data. In addition, we selected two down-regulated genes from microarray data and confirmed their expression by RT-PCR. As shown in Fig. 4, KLH11 and NCOA2 expression levels were suppressed by the indicated PPARy agonists. However, we did not observe a significant reduction of these two genes in the presence of RGZ. Since RT-PCR is not sensitive enough to detect minute differences, we performed real-time PCR to confirm our microarray data for the down-regulation of gene expression. The real-time PCR results confirmed downregulation of the KLHL-11 and NCOA2 genes (Fig. 4C). The PCR results are in general consistent with our microarray data, although RT-PCR results showed smaller differences than microarray data. Overall, these results confirmed that CSTA, DAP13, TAF12, RIS1, CDKN3 and MAGOH are induced by PPAR $\gamma$ agonists, whereas KLHL11 and NCOA2 are down-regulated by PPAR $\gamma$ agonists.

Biological profiles of PPARy agonist-induced genes. The final pattern of altered genes was evaluated by cluster analysis (Fig. 2B), and the commonly regulated genes were analyzed by ontology and signaling pathway analysis to better understand the biological phenomena involved in PPAR $\gamma$ dependency. Functional analysis of genes with a $\geq 1.5$-fold change in expression ( $\mathrm{p}<0.05$ with degree of freedom 2 ) was performed using the Onto-Express software to identify biological process and molecular function categories affected by PPAR $\boldsymbol{\gamma}$ agonists. The data analysis showed distribution of biological process (143 genes), molecular function (157 genes), and cellular component classes (144 genes) with involved genes regulated by PPAR agonists. In addition, molecular function classes were associated with antioxidant activity, binding, catalytic activity, enzyme regulator activity, signal transducer activity, structural molecular activity, transcriptional regulator activity and transporter activity. 
A

B

\section{Down-regulated}
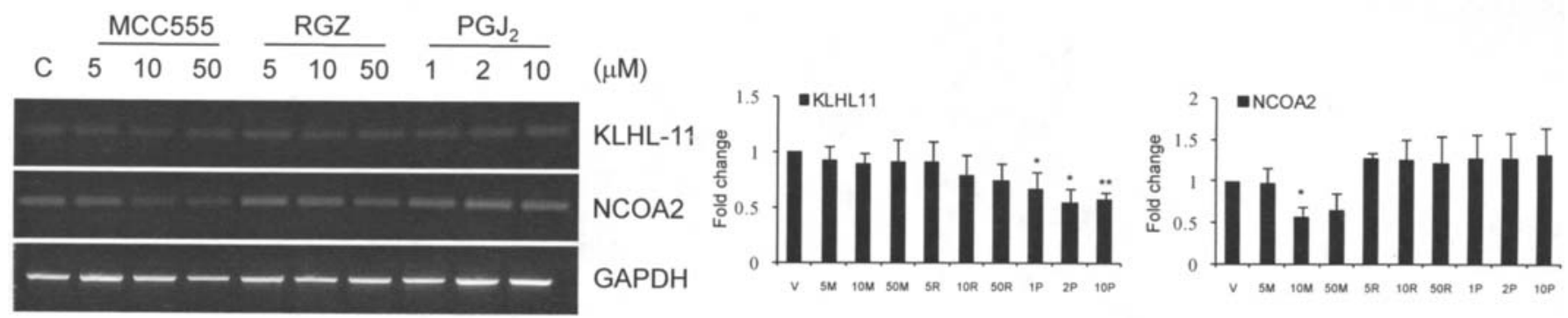

C
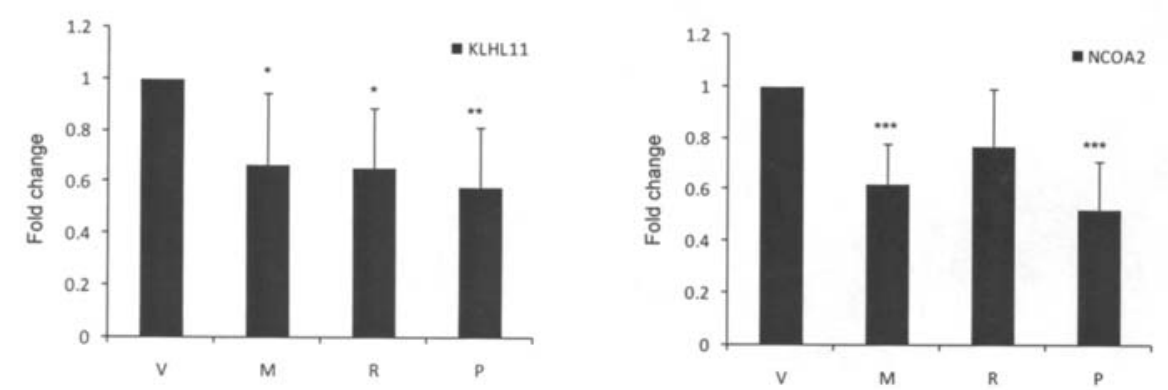

Figure 4. RT-PCR analysis of the selected PPAR $\gamma$ agonist-repressed genes in HCT-116 cells. (A) HCT-116 cells were treated by different PPAR $\gamma$ agonists for $24 \mathrm{~h}$ as described in Materials and methods in detail. Two down-regulated genes (KLHL11 and NCOA2) characterized from our microarray data were analyzed by reverse transcriptase-PCR. Genes showed repressed expression levels by treatments with MCC-555, RGZ and PGJ 2 . (B) Charts of the densitometry analysis of represented genes. Each chart represents the mean values \pm SE of three independent experiments. (C) Real-time PCR analysis of the down-regulated genes in HCT-116 cells treated with MCC-555 $(5 \mu \mathrm{M}), \operatorname{RGZ}(5 \mu \mathrm{M})$ and $\mathrm{PGJ}_{2}(1 \mu \mathrm{M})$ for $24 \mathrm{~h}$. Charts represent the mean values $\pm \mathrm{SE}$ of three independent experiments with three dilutions.

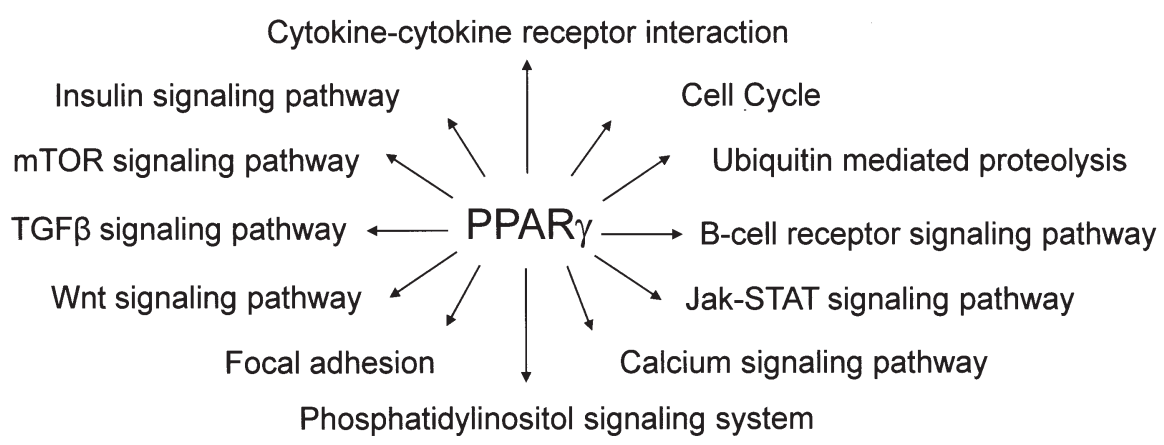

Figure 5. Scheme of pleiotropic action of PPAR $y$ on various signaling pathways in human HCT-116 colorectal cancer cells.

Furthermore, the functional importance of PPAR $\gamma$-induced target genes was analyzed by Pathway Express Software and reflected in major KEGG pathways containing previously well-identified and established genes. As shown in Fig. 5 the pathways affected by PPAR $\gamma$ agonists were cell cycle (CHEK2, MDM2 and RBX1), cytokine-cytokine receptor interaction (IL18 and VEGFB), ubiquitin-mediated proteolysis (UBE2E1 and RBX1), phosphatidylinositol signaling system (INPP5D), insulin signaling pathway (INPP5D),
Wnt signaling pathway (RBX1), TGF- $\beta$ signaling pathway (RBX1), focal adhesion (VEGFB), calcium signaling pathway (SLC25A4) and colorectal cancer pathway (APPL).

\section{Discussion}

Colorectal cancer is the third most common cancer and the third leading cause of cancer-related mortality in the United States according to the American Cancer Society. 
However, over the past decade, colorectal cancer incidence and mortality rates have decreased compared to other cancers, and it is believed that chemoprevention research on human colorectal cancer has significantly contributed to this reduced risk. It is well known that the use of non-steroidal antiinflammatory drugs (NSAIDs) decreases the risk of colorectal cancer and is very effective for chemoprevention. Data from our and other laboratories indicate that PPAR $\gamma$ agonists also induce apoptosis and have anti-tumorigenic effects in colorectal cancer $(8,9)$. PPAR $\gamma$ agonists play a pivotal role in anti-tumorigenesis in a PPAR $\boldsymbol{\gamma}$-dependent and -independent manner (1), and that is why both pathways should be considered to investigate their roles. In this regard, our data may provide an up-to-date list of genes on which PPAR $\gamma$ agonists act in a PPAR $\boldsymbol{\gamma}$-dependent and -independent manner in human colorectal cancer cells. In our experiments, we used the HEEBO long-oligo set which contains about 39,000 probes for exonic regions, and the alternative spliced transcripts microarray screening technique to identify the genes and signaling pathways commonly regulated by three different PPAR $\boldsymbol{\gamma}$ agonists in human HCT-116 colorectal adenocarcinoma cells. As shown in this study, the expression of several genes was modulated either positively (307) or negatively (32) by three PPAR $\boldsymbol{\gamma}$ agonists in HCT-116 cells, suggesting that both activation and repression can play an important role of PPAR $\boldsymbol{\gamma}$ agonists in tumorigenesis, cell growth and differentiation. MCC-555 treatment showed a unique pattern of gene expression with the least number of modified genes compared to the RGZ or $\mathrm{PGJ}_{2}$ treatments (Fig. 2B and C). One possible explanation is that MCC-555 also binds to PPAR $\alpha$ and possesses distinct properties compared to other PPAR $\gamma$ agonists. Indeed, we have shown that MCC-555 increases tumor suppressor protein NAG-1 at the post-transctiptional level, whereas TGZ affects it at the transcriptional level (16).

We have identified some of the genes that are growthrelated, or involved in tumor invasion, metastasis and apoptosis. Cystatin A or stefin A (CSTA) has been known to belong to family I of cysteine proteinase inhibitors, which are commonly down-regulated in many cancers. A large body of literature has accumulated to suggest that stefins correlate with malignancy of various murine and human tumors (19), such as lung, gastric, brain, colorectal and malignant melanoma (20). Cystatins act as tumor suppressor genes and positively relate with survival probability (21). Our data showed that the CSTA gene was up-regulated by all tested PPAR $\gamma$ agonists, which can have a beneficial effect on the treatment of colorectal cancer. Another tumor-growth related gene, CDKN3, which belongs to the dual specificity protein phosphatase family, was identified as a cyclin-dependent kinase (Cdk) inhibitor. CDKN3 has been shown to interact with the dephosphorylated Cdk-2 kinase, and thus prevent its activation (22). Our data indicate that all tested PPAR $\gamma$ agonists induced the expression of the CDKN3 gene, which may be a potential candidate for a colorectal cancer target gene to inhibit cell cycle progression.

Unlike the above-mentioned genes CSTA and CDKN3, MAGOH, TAF12, RIS1 and DAP13 genes are potentially new candidate genes associated with cancer. MAGOH is one of the eight PPAR $\boldsymbol{\gamma}$-regulated genes reported in this study, and its protein product is the human homolog of the Drosophila mago-nashi protein (23). Magoh protein plays important roles in mRNA splicing functions in the nucleus and cytoplasm. Indeed, both null mutation in flies and disruption of mRNA by RNAi in C. elegans show embryonic lethality, indicating that magoh is essential for viability (24). In our study, the expression of the MAGOH gene was up-regulated in human HCT-116 colorectal cancer cells; however, its exact biological function and regulation by PPAR $\gamma$ agonists in colorectal cancer remains to be elucidated. In contrast, little is known about DAP13 [also known as NADH dehydrogenase (ubiquinone) $1 \alpha$ subcomplex 12, NDUFA12], except that it is described as a theoretical product of a gene identified in a lung adenocarcinoma cell line that had been induced to differentiate by treatment with all trans-retinoic acid (25).

Colorectal tumors develop mostly through several pathways, which are characterized by mutations in several suppressor genes (APC, SMAD and TP53) and oncogenes (KRAS2, MYC) and in chromosome instability. Ras-induced senescence 1 (RIS1) is a novel gene identified by Barradas et al (26), and is up-regulated in association with Ras senescence. The RIS1 gene is located at chromosomal position 3 p21.3, previously defined for its tumor-suppressor activity (27); this region frequently exhibits the loss of heterozygosity in tumors, which is what confers this gene a putative role as a tumor suppressor. Moreover, mutations in the RIS1 gene are associated with a worse prognosis and development of metastasis in colorectal tumors (28). Another gene regulated by PPAR $\gamma$ agonists is TAF12 RNA polymerase II, a TATA box binding protein (TBP)-associated factor, which is an important part of the protein complex controlling the transcription by RNA polymerase II, and controlling the cell cycle and apoptosis (29). It has been shown that TAF12 interacts with ATF7, a transcription factor, and that this interaction can be modulated by another TAF protein, TAF4 (30).

Other genes characterized in our study are KLHL11 and NCOA2 that are down-regulated by PPAR $\boldsymbol{\gamma}$ agonists. KLHL11 is the human ortholog of the identified zebrafish gene, kelchlike (klhl), an important gene involved in embryogenesis. The human KLHL gene is specifically expressed in the muscles and heart, which suggests a role in muscle cytoarchitecture (31). Our microarray data also showed the down-regulation of nuclear receptor co-activator 2 gene, NCOA2, which is a family member of p160 kDa proteins involved in regulation of nuclear receptors, such as estrogen receptors and androgen receptors (32). It has been reported that NCOA2 and other cofactors including SRC-1, p300/ CBP, and Tip60 are up-regulated in advanced prostate cancer (32), suggesting that suppression of its expression is beneficial to prostate and other cancers.

Co-activators and co-repressors modulate the activity of PPAR $\boldsymbol{y}$ with influence on tumor formation. The pattern of commonly PPAR $\boldsymbol{\gamma}$ agonist-altered genes were analyzed using the Onto-Express software, and signaling pathway analysis by Pathway Express Software was done to reflect the major KEGG pathways to better understand the biological phenomena involved in PPAR $\gamma$ dependency (Fig. 5). However, KEGG pathway analyses were not able to recognize the new genes involved in well established signaling pathways. Microarray data and ontology report 
analysis showed that PPAR $\gamma$ plays an important role in cellular processes, development, growth, physiological processes, regulation of biological process, response to stimulus, antioxidant activity, binding, catalytic activity, enzyme regulator activity, signal transducer activity, structural molecular activity, transcriptional regulator activity and transporter activity.

A better understanding of the PPAR $\boldsymbol{\gamma}$ receptor and its molecular signaling pathway opens up new therapeutic prospects in treatment of colorectal cancer. Our microarray data of PPAR $\boldsymbol{\gamma}$-induced genes showed that PPAR $\boldsymbol{y}$ agonists induced pleiotropic effects on the transcriptional program of human colorectal adenocarcinoma cells, involving metabolic (e.g., amino acid and lipid metabolism) and hormonal (e.g., sterol biosynthesis), cell organization, and regulatory pathways (e.g., cytoskeletal proteins). This raises the possibility that these additional mechanisms might contribute to the anti-cancer activity of nuclear receptor agonists, perhaps in a tumor-specific and tissue-specific manner. From all of the above, it is clear that the influence of PPAR $y$ on cell cycle proliferation, differentiation and apoptosis is complex. These effects depend on the concentrations of agonists, the cell type, and/or the mutational events that predispose cancer development. The full understanding of the mechanisms requires additional laboratory studies to address the role of PPAR $\boldsymbol{\gamma}$ in tumorigenesis.

\section{Acknowledgments}

The authors thank Misty R. Bailey (The University of Tennessee, Knoxville, TN) for her technical assistance. We also thank Ron M. Evans (The Salk Institute, La Jolla, CA) for providing the tk-PPREx3-Luc reporter plasmid for our experiments. This study was supported by a grant from the National Institutes of Health (NIH-R01-CA108975) to S.J.B.

\section{References}

1. Wang T, Xu J, Yu X, Yang R and Han ZC: Peroxisome proliferator-activated receptor gamma in malignant diseases. Crit Rev Oncol Hematol 58: 1-14, 2006.

2. Vidal-Puig AJ, Considine RV, Jimenez-Linan M, et al: Peroxisome proliferator-activated receptor gene expression in human tissues. Effects of obesity, weight loss and regulation by insulin and glucocorticoids. J Clin Invest 99: 2416-2422, 1997.

3. Bren-Mattison Y, van Putten V, Chan D, Winn R, Geraci MW and Nemenoff RA: Peroxisome proliferator-activated receptorgamma [PPAR(gamma)] inhibits tumorigenesis by reversing the undifferentiated phenotype of metastatic non-small-cell lung cancer cells (NSCLC). Oncogene 24: 1412-1422, 2005.

4. Vignati S, Albertini V, Rinaldi A, et al: Cellular and molecular consequences of peroxisome proliferator-activated receptorgamma activation in ovarian cancer cells. Neoplasia 8: 851-861, 2006 .

5. Elstner E, Muller C, Koshizuka K, et al: Ligands for peroxisome proliferator-activated receptorgamma and retinoic acid receptor inhibit growth and induce apoptosis of human breast cancer cells in vitro and in BNX mice. Proc Natl Acad Sci USA 95: 8806-8811, 1998.

6. Sarraf P, Mueller E, Jones D, et al: Differentiation and reversal of malignant changes in colon cancer through PPARgamma. Nat Med 4: 1046-1052, 1998.

7. Konopleva M, Elstner E, McQueen TJ, et al: Peroxisome proliferator-activated receptor gamma and retinoid $\mathrm{X}$ receptor ligands are potent inducers of differentiation and apoptosis in leukemias. Mol Cancer Ther 3: 1249-1262, 2004.
8. Baek SJ, Wilson LC, Hsi LC and Eling TE: Troglitazone, a peroxisome proliferator-activated receptor gamma (PPAR gamma) ligand, selectively induces the early growth response-1 gene independently of PPAR gamma. A novel mechanism for its anti-tumorigenic activity. J Biol Chem 278: 5845-5853, 2003.

9. Bull AW: The role of peroxisome proliferator-activated receptor gamma in colon cancer and inflammatory bowel disease. Arch Pathol Lab Med 127: 1121-1123, 2003.

10. Okura T, Nakamura M, Takata Y, Watanabe S, Kitami Y and Hiwada K: Troglitazone induces apoptosis via the p53 and Gadd45 pathway in vascular smooth muscle cells. Eur J Pharmacol 407: 227-235, 2000.

11. Wang M, Wise SC, Leff $\mathrm{T}$ and Su TZ: Troglitazone, an antidiabetic agent, inhibits cholesterol biosynthesis through a mechanism independent of peroxisome proliferator-activated receptor-gamma. Diabetes 48: 254-260, 1999.

12. Palakurthi SS, Aktas H, Grubissich LM, Mortensen RM and Halperin JA: Anticancer effects of thiazolidinediones are independent of peroxisome proliferator-activated receptor gamma and mediated by inhibition of translation initiation. Cancer Res 61: 6213-6218, 2001

13. Davies GF, Khandelwal RL, Wu L, Juurlink BH and Roesler WJ: Inhibition of phosphoenolpyruvate carboxykinase (PEPCK) gene expression by troglitazone: a peroxisome proliferatoractivated receptor-gamma (PPARgamma)-independent, antioxidant-related mechanism. Biochem Pharmacol 62: 1071-1079, 2001.

14. Nikitakis NG, Siavash H, Hebert C, Reynolds MA, Hamburger AW and Sauk JJ: 15-PGJ2, but not thiazolidinediones, inhibits cell growth, induces apoptosis, and causes downregulation of Stat 3 in human oral SCCa cells. Br J Cancer 87: 1396-1403, 2002.

15. Eligini S, Banfi C, Brambilla M, et al: 15-deoxy-delta12,14Prostaglandin $\mathrm{J} 2$ inhibits tissue factor expression in human macrophages and endothelial cells: evidence for ERK1/2 signaling pathway blockade. Thromb Haemost 88: 524-532, 2002.

16. Yamaguchi K, Lee SH, Eling TE and Baek SJ: A novel peroxisome proliferator-activated receptor gamma ligand, MCC-555, induces apoptosis via posttranscriptional regulation of NAG-1 in colorectal cancer cells. Mol Cancer Ther 5: 1352-1361, 2006.

17. Yuan JS, Reed A, Chen F and Stewart CN Jr: Statistical analysis of real-time PCR data. BMC Bioinformatics 7: 85, 2006.

18. Nixon JB, Kamitani H, Baek SJ and Eling TE: Evaluation of eicosanoids and NSAIDs as PPARgamma ligands in colorectal carcinoma cells. Prostaglandins Leukot Essent Fatty Acids 68: 323-330, 2003.

19. Keppler D: Towards novel anti-cancer strategies based on cystatin function. Cancer Lett 235: 159-176, 2006.

20. Kos J and Lah TT: Cysteine proteinases and their endogenous inhibitors: target proteins for prognosis, diagnosis and therapy in cancer (review). Oncol Rep 5: 1349-1361, 1998.

21. Strojan P, Budihna M, Smid L, et al: Prognostic significance of cysteine proteinases cathepsins $\mathrm{B}$ and $\mathrm{L}$ and their endogenous inhibitors stefins $A$ and $B$ in patients with squamous cell carcinoma of the head and neck. Clin Cancer Res 6: 1052-1062, 2000.

22. Yeh CT, Lu SC, Chao CH and Chao ML: Abolishment of the interaction between cyclin-dependent kinase 2 and Cdkassociated protein phosphatase by a truncated KAP mutant. Biochem Biophys Res Commun 305: 311-314, 2003.

23. Zhao XF, Colaizzo-Anas T, Nowak NJ, Shows TB, Elliott RW and Aplan PD: The mammalian homologue of mago-nashi encodes a serum-inducible protein. Genomics 47: 319-322, 1998.

24. Boswell RE, Prout ME and Steichen JC: Mutations in a newly identified Drosophila melanogaster gene, mago-nashi, disrupt germ cell formation and result in the formation of mirror-image symmetrical double abdomen embryos. Development 113: 373-384, 1991.

25. Skehel JM, Fearnley IM and Walker JE: NADH:ubiquinone oxidoreductase from bovine heart mitochondria: sequence of a novel 17.2-kDa subunit. FEBS Lett 438: 301-305, 1998.

26. Barradas M, Gonos ES, Zebedee Z, et al: Identification of a candidate tumor-suppressor gene specifically activated during Ras-induced senescence. Exp Cell Res 273: 127-137, 2002 . 
27. Kok K, Naylor SL and Buys CH: Deletions of the short arm of chromosome 3 in solid tumors and the search for suppressor genes. Adv Cancer Res 71: 27-92, 1997.

28. Iglesias D, Fernandez-Peralta AM, Nejda N, et al: RIS1, a gene with trinucleotide repeats, is a target in the mutator pathway of colorectal carcinogenesis. Cancer Genet Cytogenet 167: 138-144, 2006.

29. Martinez E: Multi-protein complexes in eukaryotic gene transcription. Plant Mol Biol 50: 925-947, 2002.

30. Hamard PJ, Dalbies-Tran R, Hauss C, Davidson I, Kedinger C and Chatton B: A functional interaction between ATF7 and TAF12 that is modulated by TAF4. Oncogene 24: 3472-3483, 2005.
31. Wu YL and Gong Z: A novel zebrafish kelchlike gene klhl and its human ortholog KLHL display conserved expression patterns in skeletal and cardiac muscles. Gene 338: 75-83, 2004.

32. Powell SM, Christiaens V, Voulgaraki D, Waxman J, Claessens F and Bevan CL: Mechanisms of androgen receptor signalling via steroid receptor coactivator-1 in prostate. Endocr Relat Cancer 11: 117-130, 2004. 